\title{
Attachment Style and the Stability of Self-worth Following Life Events
}

\author{
Jaclyn A. Ludmer, Phillip A. Vernon, Robert C. Gardner \\ The University of Western Ontario, Ontario, Canada
}

\begin{abstract}
This study explored the stability of self-worth among avoidantly and anxiously attached individuals in achievement and social domains. Undergraduate students $(n=180)$ completed measures of attachment style and were given a list of life events. Participants rated the extent to which their global self-worth would increase or decrease as a result of each event. Avoidantly attached individuals reported relatively stable levels of self-worth, whereas anxiously attached individuals reported heightened self-worth from positive interpersonal events and lowered self-worth from negative interpersonal events. Results suggest that avoidantly attached individuals may not create contingencies of self-worth, whereas anxiously attached individuals may create contingencies of self-worth within the social domain.

Keywords: attachment styles, self-worth, self-worth stability, contingent self-worth
\end{abstract}

\section{Introduction}

Every situation we meet with in life is construed in terms of the representational models we have of the world about us and of ourselves. (Bowlby, 1980, p. 229)

Self-worth and personality are intricately linked (Robins, Tracy, Trzesniewski, Potter, \& Gosling, 2001; Baumeister, Tice, \& Hutton, 1989). Attachment theory, maintaining that an individual's self-views are a product of early caregiver interactions, provides an ethological approach to personality development (Ainsworth \& Bowlby, 1991; Shaver, Collins, \& Clark, 1996). Repeated experiences with an insensitive primary caregiver can foster an insecure attachment style that may promote an unstable sense of self-worth that persists across the lifespan (Bowlby, 1969, 1980; Bretherton \& Munholland, 2008; Morley \& Moran, 2011; Sroufe, 2005). Although the relation between attachment style and self-worth has been implicitly assumed and in some cases demonstrated, the specific nature of this relationship needs to be more clearly investigated (Bylsma, Cozzarelli, \& Sumer, 1997; Park, Crocker, \& Mickelson, 2004), and the current study addressed this issue.

\section{Contingencies of Self-worth}

Self-worth and personality are highly interactive (Robins et al., 2001). For example, an individual's self-views impact their affect (Pelham \& Swann, 1989), behavior in particular situations (Crocker \& Park, 2004; Sroufe, 2005), interpersonal style (Feeney, 2008; Sroufe, 2005), and goals (Crocker \& Wolfe, 2001). Conversely, an individual's behavioral tendencies (i.e., personality) critically impact how they perceive and

Jaclyn A. Ludmer, The University of Western Ontario.

Phillip A. Vernon, Ph.D., The University of Western Ontario.

Robert C. Gardner, Ph.D., The University of Western Ontario. 
evaluate themselves (Robins et al., 2001; Bretherton \& Munholland, 2008). Contingencies of self-worth and the resulting tenuous sense of self-regard may be particularly important for understanding the relationship between self-worth, personality, and behavior (Crocker \& Park, 2004; Crocker \& Wolfe, 2001). A contingency of self-worth is a category of outcomes on which an individual has staked their self-esteem: The individual's view of their own value or competence depends on perceived success or failure with regard to such outcomes (Crocker \& Wolfe, 2001). For example, an individual may feel that their value depends on others' acceptance and approval, and may create a contingency of self-worth such as "If I get invited to the party, then I am a likeable person". As long as this individual perceives that this need is met (i.e., that they are likeable), they will experience a sense of self-worth. However, if this individual does not fulfill their self-worth standard (i.e., they were not invited to the party), they may draw general conclusions about themselves on the basis of the single negative outcome, and reason that they are worthless overall (Crocker \& Wolfe, 2001; Kuiper, Olinger, \& MacDonald, 1988). Thus, individuals who create contingencies of self-worth characteristically experience an unstable sense of self-worth, feeling heightened self-worth following perceived success, but lowered self-worth following perceived failure.

There are two overarching sources of self-worth: social acceptance and successful action (Brennan \& Bosson, 1998; Franks \& Marolla, 1976; Tafarodi \& Swann, 1995). Deriving self-worth from social acceptance involves gaining or maintaining approval from others and then internalizing this as a sense of positive self-regard. Deriving self-worth from successful action involves perceiving one's own competence or environmental mastery and then internalizing this as a sense of positive self-regard (Tafarodi \& Swann, 1995). Researchers have suggested that pursuits of self-worth may be "domain-specific" and occur only in domains in which self-worth is emphasized (Crocker \& Wolfe, 2001; James, 1890; Park, Crocker, \& Mickelson, 2004). For example, an individual may base global feelings of self-worth on successful action, but not on social acceptance, and may therefore create contingencies of self-worth only within the achievement-domain, as opposed to the social domain. Attachment theory provides a theoretical context for understanding how a domain-specific contingent sense of self-worth might develop, and how it may impact an individual's goals and behavior.

\section{Attachment, IWMs (Internal Working Models), and Self-perceptions}

Attachment theory maintains that, based on the quality of early interactions with a primary caregiver, a child develops an IWM of the self, the other, and relationships in general (Bowlby, 1969; 1973; 1980). Since self-representations are constructed based on views of interpersonal interactions (Bowlby, 1980; Baldwin, 1997; Baldwin, Fehr, Keedian, Seidel, \& Thompson, 1993), the level of sensitivity in mother-infant interactions is theorized to serve as the foundation of infants' emerging sense of worthiness (Ainsworth, Blehar, Waters, \& Wall, 1978; Bretherton \& Munholland, 2008; Morley \& Moran, 2011). Secure attachment relationships, having been linked to consistently sensitive and responsive parenting, are thought to provide the infant with a stable view of others as trustworthy and reliable, which may foster a complementary and stable view of the self as worthy of unconditional love and affection (Bowlby, 1980; Goldberg, 2000). Conversely, insensitive parenting can foster insecure attachment and prevent the infant from establishing a stable and positive sense of self-worth (Bowlby, 1980; Bretherton \& Munholland, 2008; Morley \& Moran, 2011).

An individual's history of being responded to by close others in childhood is theorized to impact future relationships (Bowlby, 1969; Hamilton, 2000; Waters, Merrick, Treboux, Crowell, \& Albersheim, 2000). In adulthood, attachment insecurity is described along two dimensions: avoidance, the extent to which the 
individual feels discomfort in relationships, and anxiety, the extent to which the individual worries about the availability of others (Hazan \& Shaver, 1987; Shaver, Hazan, \& Bradshaw, 1988). Avoidantly attached individuals are likely to have had caregivers who were consistently rejecting or intrusive and, as a result, these individuals prefer to avoid intimacy and refrain from depending on others (Ainsworth et al., 1978; Bretherton \& Munholland, 2008; Goldberg, 2000). Anxiously attached individuals are likely to have had inconsistently responsive caregivers and, as a result of these unpredictable messages of love and rejection, strive for emotional intimacy but persistently worry that others will reject them.

Consistent with attachment theory, studies have established links between insecure attachment and a low sense of global self-worth (Collins \& Read, 1990; Feeney \& Noller, 1990; Park et al., 2004). Empirical studies have also supported that attachment styles influence the stability of an individual's self-worth throughout the lifespan. For example, Sroufe, Egeland, Carlson, and Collins (2005) gave children a barrier box task, which involves attempting to open a locked box in order to retrieve a set of toys. Since the task was nearly impossible to complete, success was judged as the extent to which the child persisted in the face of challenge. Relative to children with secure attachment histories, children with insecure attachment histories were less likely to show task persistence. The lack of persistence in the face of challenge suggests that these children have an unstable sense of self-worth (Morley \& Moran, 2011; Ziegert, Kistner, Castro, \& Robertson, 2001). Accordingly, Sroufe et al. (2005) found that the insecurely attached children, relative to the securely attached children, had lower teacher-rated self-esteem.

On a lexical decision task, using adults, Baldwin et al. (1993) found that securely attached participants were faster to identify words representing positive interpersonal factors, such as acceptance, while insecurely attached participants were quicker to identify words representing negative interpersonal outcomes, such as rejection. Thus, IWMs of attachment may constantly and unconsciously bias perceptions and promote a focus on relationship-related phenomena. Further, Baldwin and Sinclair (1996) examined participants' "if ... then" contingencies of self-worth on a lexical decision task. On each trial, participants were presented with a success or failure context word and then made a word-nonword judgment on a different letter string, which was sometimes a target word related to interpersonal outcomes. These researchers found that, for low-self-esteem participants, success and failure contexts facilitated the processing of acceptance and rejection target words respectively. This suggests that participants with low self-esteem perceived interpersonal acceptance as being contingent on successes and failures. These researchers concluded that relational schemas may contribute to the construction of self-worth contingencies (Baldwin et al., 1993; Baldwin \& Sinclair, 1996). Their results suggest that insecurely attached individuals may hold unstable and contingent senses of self-worth, whereas securely attached individuals may be more likely to base feelings of self-worth on stable, internal characteristics and thus less likely to create contingencies of self-worth (Elliot \& Reis, 2003; Morley \& Moran, 2011).

\section{Attachment Style and Domain-Specific Contingencies of Self-worth}

When exploring the relationship between attachment security and contingencies of self-worth, it is important to differentiate between individuals with avoidant and anxious attachment styles, since these individuals appear to base feelings of self-worth in unique domains (Blatt \& Homann, 1992; Gamble \& Roberts, 2005; Morley \& Moran, 2011) and derive self-esteem from different sources (Hepper \& Carnelley, 2010; Park et al., 2004). More specifically, individuals with avoidant attachment styles may base feelings of self-worth 
primarily in the achievement domain, while anxiously attached individuals may do so primarily in the social domain (Gamble \& Roberts, 2005; Morley \& Moran, 2011; Park et al., 2004). In support of this, Hazan and Shaver (1990) found avoidantly attached individuals to focus on work achievements as a way to avoid social interactions and Brennan and Morris (1997) found these individuals to value self-competence. Zuroff and Fitzpatrick (1995) have also found that avoidant attachment was associated with autonomy. Autonomy refers to the extent to which an individual is motivated by a set of personalized criteria for measuring achievements, and is intolerant of interference in the pursuit of such goals (Frewen \& Dozois, 2006). The notion that the achievement domain has a particularly strong impact on feelings of self-worth among autonomous individuals (Blatt \& Homann, 1992; Zuroff \& Fitzpatrick, 1995) further supports the idea that the achievement-domain may be important to the self-views of avoidantly attached individuals. Moreover, two studies examined the feedback-seeking preferences of individuals with different attachment styles: Hepper and Carnelley (2010) found evidence that, despite their overall bias towards seeking negative feedback, avoidantly attached individuals sought positive feedback about autonomy, and Brennan and Bosson (1998) found these individuals to avoid receiving social feedback from others. Thus, autonomy and the achievement-domain may be particularly important to the self-worth of avoidantly attached individuals, while the social domain may be less relevant. This would suggest that avoidantly attached individuals may experience an unstable sense of self-worth only within the achievement domain and may limit contingencies of self-worth to the achievement domain.

Conversely, individuals with anxious attachment styles have been found to strive for social approval and neglect achievement-related activities (Goldberg, 2000; McElwain, Cox, Burchinal, \& Macfie, 2003; Sourfe, 2005). For example, McElwain et al. (2003) examined the behavior of children in a room with toys and their parent. Children with anxious attachment histories were found to completely neglect the toys and to focus their resources on eliciting attention from their caregiver. This suggests that these children needed the attention and approval of their caregiver in order to be self-assured. In line with these suggestions, Evraire and Dozois (n.d.) linked anxious attachment to ERS (excessive reassurance seeking) from close others, and Hepper and Carnelley (2010) found anxiously attached individuals to seek interpersonal-related over competence-related feedback from close others following social and problem-solving tasks. Hepper and Carnelley (2010) suggested that anxiously attached individuals persistently seek out social-related feedback from others since the social domain is crucial to their self-views. Other studies have emphasized the similarities between anxiously attached individuals and sociotropic individuals (Blatt \& Homann, 1992; Zuroff \& Fitzpatrick, 1995). Sociotropy refers to the extent to which an individual is concerned with how he/she is perceived by others and is motivated to obtain others' approval (Frewen \& Dozois, 2006). Frewen and Dozois (2006) suggested that the social domain had a particularly strong impact on feelings of self-worth among sociotropic individuals. The associations between sociotropy and attachment anxiety (Blatt \& Homann, 1992; Zuroff \& Fitzpatrick, 1995) suggested that anxiously attached individuals may also show these social-oriented biases and may limit contingencies of self-worth to the social domain.

Taken together, avoidantly and anxiously attached individuals may have failed to establish a positive and stable sense of self-worth (Bowlby, 1980; Morley \& Moran, 2011; Sroufe, 2005). They may therefore create contingencies of self-worth (i.e., experience fluctuating levels of self-worth based on event outcomes) in achievement and social domains respectively. 


\section{The Current Study}

Although studies have examined domain-specific feedback seeking and importance ratings among anxiously and avoidantly attached individuals (Brennan \& Bosson, 1998; Brennan \& Morris, 1997; Hepper \& Carnelley, 2010), only one study has directly examined how individuals with unique attachment styles differ in creating contingencies of self-worth within a particular domain (Park et al., 2004). Park et al. (2004) gave participants the contingent self-worth scale (Crocker, Luhtanen, Cooper, \& Bouvrette, 2003), which assesses whether participants create contingencies of self-worth based on physical appearance, approval from others, outdoing others in competition, academic competence, family support, virtue, and God's love. This scale includes general statements about contingent self-worth for each of the seven topics, such as "my self-esteem depends on the opinions others hold of me”. Park et al.’s (2004) results supported that, relative to insecurely attached individuals, securely attached individuals were more likely to derive self-esteem from sources that are relatively unconditional and not dependent on others' reactions (i.e., from family support). However, the authors acknowledged that there are many other areas of contingency not measured in their study that may be related to attachment styles. For example, although no effect of academic competence was found, Park et al. (2004) cautioned against ruling out the achievement domain as a potential source of self-worth for insecurely attached individuals, given other research within this area (Brennan \& Bosson, 1998; Brennan \& Morris, 1997; Hepper \& Carnelley, 2010). It could be that self-reliance, or another factor, may be more relevant than academic success to the achievement-related self-worth contingencies of insecurely attached individuals.

As such, we decided to test the theory with a different scale - the life events of college students scale-which consists of a list of 112 positive social-related events, positive achievement-related events, negative social-related events, and negative achievement-related events (Sandler \& Lakey, 1982). We believe that this scale will provide a better test of the theory because it allows participants to directly rate how they think their self-worth would change as a result of many different, specific life events, rather than responding to statements that directly ask about their contingent self-worth for seven general topics, as they would with the contingent self-worth scale (Crocker et al., 2003). High levels of fluctuating self-worth ratings on the life events scale (i.e., unstable levels of self-worth that change based on event outcomes) were operationalized as a highly contingent sense of self-worth.

It was expected that individuals with avoidant attachment styles would show contingent self-worth in the achievement-domain (Hypothesis 1). That is, individuals higher in avoidant attachment were expected to report larger decrements in global self-worth from negative achievement-based events and larger increases in global self-worth from positive achievement-based events, relative to those lower in avoidant attachment. It was also expected that individuals with anxious attachment styles would show contingent self-worth in the social-domain (Hypothesis 2). That is, individuals higher in anxious attachment were expected to report larger decrements in global self-worth from negative social-based events and larger increases in global self-worth from positive social-based events, relative to those lower in anxious attachment.

\section{Method}

\section{Participants}

A total of 180 undergraduate students were recruited for this study through Western University's psychology research pools. Forty of these participants were recruited through the summer pool and were entered in a draw for an iPod nano for their participation. The remaining 140 participants were recruited 
through the fall pool and, for their involvement, received class credit for their first year psychology course. Participants' ages ranged from 17 to 33 years $(M=19.03$; $S D$ (standard deviation) $=2.35)$. There were 133 females, 45 males, and 2 unspecified.

\section{Materials}

ECR-R (Experiences in close relationships-revised) (Fraley, Waller, \& Brennan, 2000). The ECR-R is a revised version of Brennan, Clark, and Shaver's (1998) ECR (experiences in close relationships) questionnaire. It consists of 36-items designed to assess individual differences in anxious attachment, the extent to which individuals are insecure about their partner's availability and responsiveness, and avoidant attachment, the extent to which individuals are uncomfortable being close to others. Participants rate each item on a 7-point scale ranging from 1 ("Disagree strongly") to 7 (“Agree strongly”) based on how they generally experience their close relationships (friends, parents, and partner), rather than based on their current relationships. An example of an item is "I am nervous when others get close to me". The ECR-R has established reliability as well as criterion and predictive validity (Sibley, Fischer, \& Liu, 2005). Sibley et al. (2005) considered the ECR-R to be the most appropriate self-report measure of adult attachment currently available. Cronbach's alpha $(\alpha)$ was used as a measure of internal consistency among the items within each category and was very good for both attachment anxiety ( $\alpha=0.93$ ) and attachment avoidance $(\alpha=0.91)$.

LECSS (Life events of college students scale) (Sandler \& Lakey, 1982). The LECSS is a 112-item list of both positive and negative life events developed to be relevant to a college student population (e.g., "quit job" and "started a love relationship"). For the purpose of the current study, participants were asked to rate the extent to which the event would change their feeling of overall self-worth on a 5-point Likert scale ranging from 1 ("Large decrease") to 5 ("Large increase"), and whether the event occurred in the past 12 months. If the event did not occur in the past 12 months, participants were asked to imagine that the event did occur and to fill out the questionnaire accordingly. For the purpose of the current study, each event on the LECCS was nominally categorized as either positive or negative, and as either interpersonal or achievement by five independent raters. The raters were honors psychology students and research assistants (Frewen \& Dozois, 2006). Only events in which there was perfect agreement between raters were used in the subscale division and this resulted in 110 events (two events were dropped). Four nonover lapping categories were created: positive interpersonal events, which consisted of 20 items (e.g., "started a love relationship"), positive achievement events, which consisted of 39 items (e.g., "significantly improved your financial status”), negative interpersonal events, which consisted of 27 items (e.g., "terminated intimate relationship”), and negative achievement events, which consisted of 24 items (e.g., “increased problem with academic performance”). Participants' average self-worth scores were calculated for each category.

\section{Procedure}

Participants were self-selected for the study through the University of Western Ontario's web-based research participation pool. Upon contact, each participant was given a link to a Survey Monkey online survey page. This page included a letter of information highlighting the purpose of the current study. Participants were then asked to read a consent form and click on a button to confirm their consent. Participants then completed the survey, which included demographic questions, the ECR-R, and the LECSS. The entire survey took participants approximately one hour to complete.

After completing the questions, the website directed participants to a debriefing page, which provided 
them with more details concerning the nature of the study and the importance of each student's participation and contribution. Participants were given the researchers' contact information and were invited to ask the researchers any questions about the study.

\section{Results}

Descriptive statistics for the variables of interest are summarized in Table 1. Correlations between variables of interest can be found in Table 2. The purpose of the current study was to determine whether the relation of self-worth to the domain under consideration (interpersonal or achievement) was influenced by either of two variables: attachment anxiety and attachment avoidance (Hypotheses 1 and 2). The valences (positive or negative) of the LECCS events within the domains were also taken into account. The data therefore were analyzed in terms of a three factor analysis of variance with repeated measures on two of the factors, domain and valence, and a third factor, either anxiety or avoidance. Because the third factor was a continuous variable, the analysis was performed using multiple regression as proposed by Cohen (1968) and J. Cohen and P. Cohen (1975). Each of the third factor scores (attachment anxiety or avoidance) was centered.

Table 1

Means and SDs for Key Variables

\begin{tabular}{lcc}
\hline Variable & $M$ & $S D$ \\
\hline Anxious attachment & 3.66 & 1.10 \\
Avoidant attachment & 3.86 & 1.01 \\
MRSW positive interpersonal events & 3.78 & 0.42 \\
MRSW negative interpersonal events & 1.98 & 0.44 \\
MRSW positive achievement events & 3.92 & 0.43 \\
MRSW negative achievement events & 2.00 & 0.41 \\
Percentage of events labeled interpersonal & 58.92 & 16.80 \\
Percentage of events labeled achievement & 41.08 & 16.80 \\
\hline
\end{tabular}

Note. MRSW = Mean rating of self-worth.

Table 2

Correlation Coefficients Between Key Variables

\begin{tabular}{|c|c|c|c|c|c|c|c|}
\hline & 2 & 3 & 4 & 5 & 6 & 7 & 8 \\
\hline 1. Anxious attachment & - & & & & & & \\
\hline 2. Avoidant attachment & 0.11 & - & & & & & \\
\hline 3. MRSW positive interpersonal events & 0.03 & -0.12 & - & & & & \\
\hline 4. MRSW negative interpersonal events & -0.09 & 0.14 & $-0.27^{* * *}$ & - & & & \\
\hline 5. MRSW positive achievement events & -0.04 & $-0.12^{*}$ & $0.80^{* * *}$ & $-0.28^{* * *}$ & - & & \\
\hline 6. MRSW negative achievement events & -0.00 & 0.07 & $-0.23^{* *}$ & $0.69^{* * *}$ & $-0.26^{* *}$ & - & \\
\hline 7. Percentage of events labeled I & -0.06 & -0.03 & -0.11 & -0.10 & $-0.18^{*}$ & -0.04 & - \\
\hline 8. Percentage of events labeled A & 0.06 & 0.03 & 0.11 & $0.1018^{*}$ & 0.04 & $-1.00^{* * *}$ & - \\
\hline
\end{tabular}

For the two regression analyses, the effects of domain and valence and the domain $\times$ valence interaction are identical because they reflect the means of self-worth for the four cells of positive interpersonal and positive achievement, negative interpersonal and negative achievement (see Table 3). Significant effects were obtained for domain $\left(F_{(1,155)}=22.12, p<0.001\right)$, valence $\left(F_{(1,155)}=1\right.$,309.94, $\left.p<0.001\right)$, and the domain $\times$ valence 
interaction $\left(F_{(1,155)}=12.20, p<0.01\right)$. In light of the significant domain $\times$ valence interaction, main effects should be interpreted with caution. The main effect of domain revealed that the mean for self-worth for interpersonal events (2.88) was significantly lower than that for achievement events (2.96). That is, individuals tended to report higher self-worth from achievement events relative to interpersonal events. The main effect of valence revealed that the mean for self-worth from positive events (3.85) was significantly higher than that for negative events (1.99). That is, individuals tended to report higher self-worth from positive events relative to negative events. In light of the domain $\times$ valence interaction, the means in Table 3 will be focused on. As can be seen in Table 3, the mean self-worth rating for positive achievement events is higher than the mean self-worth rating for positive interpersonal events while there is no difference between the mean self-worth ratings for negative events. That is, individuals tended to report higher self-worth from achievement events relative to interpersonal events when the events were positive, but when the events were negative, individuals tended to report similar levels of self-worth from interpersonal and achievement events.

Table 3

Mean Self-worth Ratings

\begin{tabular}{lll}
\hline & Interpersonal & Achievement \\
\hline Positive & 3.78 & 3.92 \\
Negative & 1.98 & 2.00 \\
\hline
\end{tabular}

Table 4

Regression Coefficients of Self-worth on Attachment Avoidance

\begin{tabular}{lcc}
\hline & Interpersonal & Achievement \\
\hline Positive & -0.051 & -0.07 \\
Negative & 0.058 & 0.028 \\
\hline
\end{tabular}

When attachment avoidance was the third factor in the analysis, there was also a significant two-way interaction between valence and attachment avoidance $\left(F_{(1,155)}=4.31, p<0.05\right)$. Table 4 presents the regression coefficients of self-worth on avoidance for each of the four conditions, but as the three-way interaction was not significant, attention will focus on the significant two-way interaction between valence and avoidance. The valence $\times$ avoidance interaction is reflected in the difference between the mean slopes of self-worth against avoidance for positive events (-0.06) and negative events (0.04). For positive events, there was a negative relationship between avoidance and self-worth, whereas for negative events, the relationship was positive. That is, as individuals scored higher on attachment avoidance, they tended to report lower levels of self-worth from positive events, but higher levels of self-worth from negative events.

When attachment anxiety was the third factor in the analysis, there was also a significant three-way interaction between domain, valence, and attachment anxiety $\left(F_{(1,155)}=3.96, p<0.05\right)$. The three-way interaction is indicated by the slopes of the regressions of self-worth on anxiety in each of the four cells shown in Table 5 and plotted in Figure 1. As can be seen in Table 5, the regression coefficients are very low but the pattern is consistent with the current study's hypotheses. Note that the relationship of self-worth to anxiety decreases from interpersonal to achievement in the positive domain, whereas it increases from interpersonal to achievement in the negative domain. That is, for positive interpersonal events, there was a positive relationship between anxiety and self-worth, whereas for negative interpersonal events, the relationship was negative. However, for positive achievement events, there was a negative relationship between anxiety and self-worth, 
whereas for negative achievement events, the relationship was zero. In other words, as individuals scored higher on attachment anxiety, they tended to report higher levels of self-worth from positive interpersonal events, but lower levels of self-worth from negative interpersonal events. However, as individuals scored higher on attachment anxiety, they also tended to report lower levels of self-worth from positive achievement events, but average levels of self-worth from negative achievement events.

Table 5

Regression Coefficients of Self-worth on Attachment Anxiety

\begin{tabular}{lcc}
\hline & Interpersonal & Achievement \\
\hline Positive & 0.012 & -0.015 \\
Negative & -0.037 & 0.000 \\
\hline
\end{tabular}

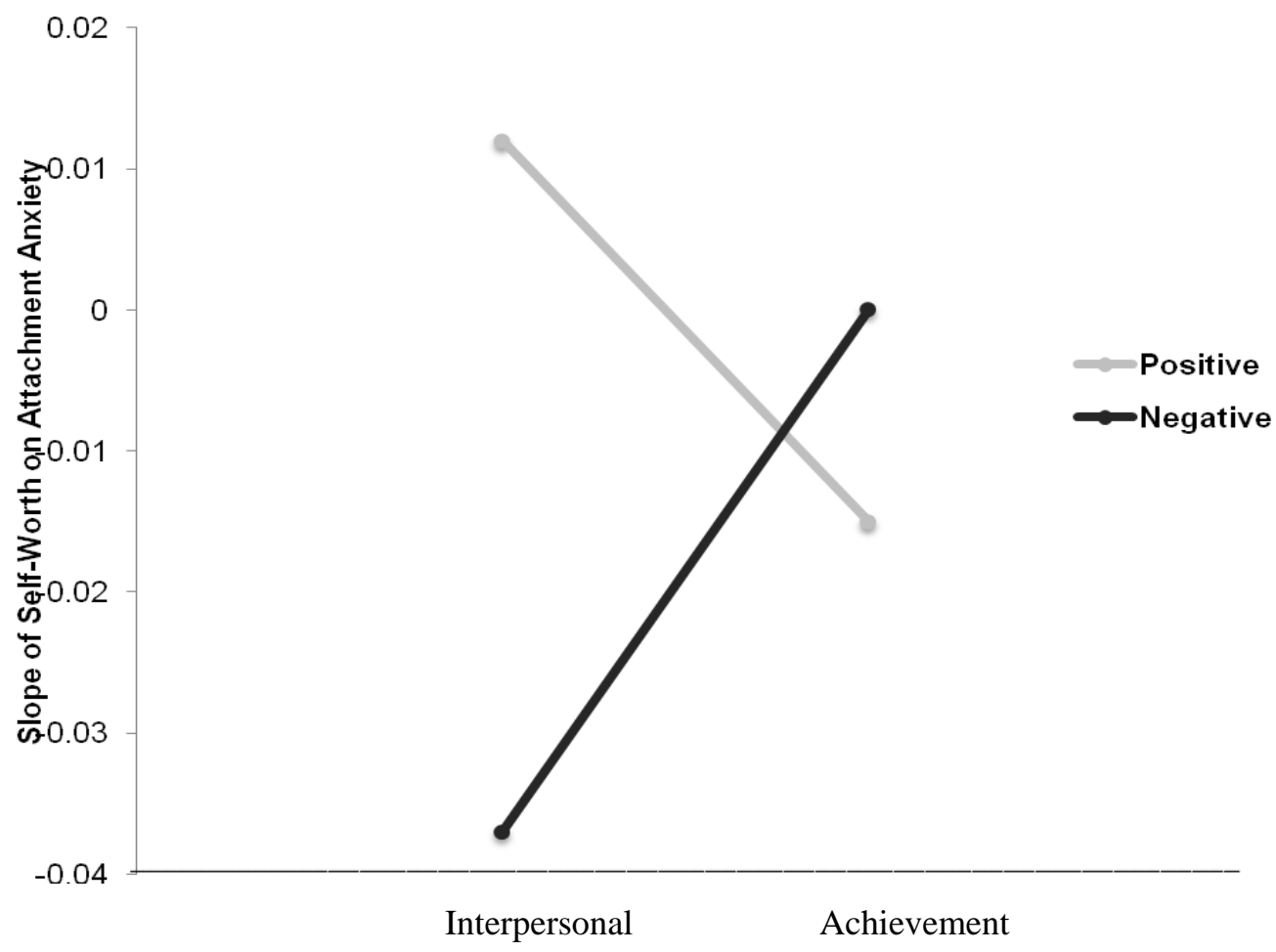

Figure 1. Anxiety $\times$ valence $\times$ domain interaction. Numbers represent the slopes of the regressions of self-worth ratings on attachment anxiety for positive interpersonal events, negative interpersonal events, positive achievement events, and negative achievement events.

\section{Discussion}

The current study sought to gain a comprehensive understanding of how insecure attachment might influence the stability of self-worth in social and achievement domains. As discussed below, results suggest that avoidantly attached individuals may not be prone to creating contingencies of self-worth, whereas anxiously attached individuals may create contingencies of self-worth within the social domain. The current results have implications for the literature on attachment style differences in self-worth as well as on the developmental origins of contingencies of self-worth. 


\section{Avoidant Attachment and Self-worth}

Hypothesis 1 was not supported as individuals high in attachment avoidance reported relatively stable levels of self-worth following both social and achievement-related life events. These results suggest that avoidantly attached individuals may not create contingencies of self-worth. These results appear to be inconsistent with theoretical suggestions that insecurely attached individuals failed to develop a stable internal sense of self-worth (Bowlby, 1969, 1973, 1980; Park et al., 2004; Morley \& Moran, 2011) and empirical findings linking both anxious and avoidant insecure attachment to lower levels of self-esteem (Collins \& Read, 1990; Feeney \& Noller, 1990; Park et al., 2004). On the other hand, the current results are consistent with Mikulincer's (1995) finding that, although securely attached individuals had a more balanced and coherent self-structure than insecurely attached individuals, both securely and avoidantly attached individuals had more positive views of themselves than anxiously attached individuals. Nevertheless, these positive self-views may not reflect the existence of a truly high and stable self-esteem. For example, Mikulincer (1995) suggested that the self-esteem of avoidantly attached individuals was so fragile that they repressed discoveries of even the slightest flaws. Accordingly, Morley and Moran (2011) suggested that some avoidantly attached individuals, in response to patterns of criticism and rejection from their caregivers, developed a strategy involving self-reliance and ignored self-deficiencies while focusing on the attributes of independence that contribute to positive views of the self. Thus, it may be that some avoidantly attached individuals focus on their positive attributes and refrain from creating contingencies of self-worth in order to avoid discoveries of any flaws (Mikulincer, 1995).

It may also be important to differentiate between unique types of avoidant attachment. Bowlby (1973) suggested that IWMs have two components: models of the self (worthy or unworthy of love) and models of others (trustworthy and responsive or unreliable and rejecting). Bartholomew and Horrowitz (1991) created four attachment classifications by crossing these two components: secure (positive self model and positive other model), preoccupied (negative self-model and positive other model), dismissing-avoidant (positive self-model and negative other model), and fearful-avoidant (negative self-model and negative other model). Both dismissing-avoidant and fearful-avoidant styles are characterized by distrust of others, however, only the fearful-avoidant style is also characterized by a belief that the self is unlovable. Bartholomew and Horrowitz (1991) found those with secure and dismissing-avoidant styles to have higher levels of global self-esteem than those with preoccupied or fearful-avoidant styles. Bylsma, Cozzarelli, and Sumer (1997) replicated this finding, pointing to the negative model of the self to account for why fearful-avoidant but not dismissing-avoidant individuals have lower global self-esteem. These findings suggest that fearful-avoidant but not dismissing-avoidant individuals may create contingencies of self-worth and experience heightened self-worth from a positive life event and reduced self-worth from a negative life event. Thus, in order to better understand the relationship between avoidant attachment and contingent self-worth, the current study should be replicated using a measure that differentiates between dismissing-avoidant and fearful-avoidant attachment.

\section{Anxious Attachment and Self-worth}

Hypothesis 2 was supported, as individuals higher in attachment anxiety, relative to those lower in attachment anxiety, reported larger increases in global self-worth as a result of positive social-related life events and larger decreases in global self-worth as a result of negative social-related life events. This suggests that anxiously attached individuals create contingencies of self-worth in the social domain (e.g., "If this social event 
has a positive outcome, then I am valuable but if it does not, then I am worthless”) (Crocker \& Park, 2004; Crocker \& Wolfe, 2001). These results are consistent with attachment theory and previous suggestions that anxiously attached individuals have low self-esteem (Collins \& Read, 1990; Feeney \& Noller, 1990; Park et al., 2004) and strive for a sense of self-worth by gaining social approval (Hepper \& Carnelley, 2010; Morley \& Moran, 2011; Park et al., 2004). Attachment theory suggests that, as a reaction to early experiences of inconsistently responsive parenting, anxiously attached individuals feel a lack of control over their own social environments and persistently worry about abandonment (Ainsworth et al., 1978; Bowlby, 1980). These worries may lead them to create contingencies of self-worth by striving for others' approval in order to gain a sense of relationship security and worthiness.

Other research has linked anxious attachment to ERS, a maladaptive behavior characteristic of individuals with depression (Abela, Hankin, Haigh, Adams, Vinokuroff, \& Trayhem, 2005; Davila, 2001; Evraire \& Dozois, n.d.; Hammen, 1991; Timmons \& Joiner, 2008; Shaver, Schachner, \& Mikulincer, 2005). ERS is defined as "the relatively stable tendency to excessively and persistently seek assurances from others that one is lovable and worthy, regardless of whether such assurance has already been provided” (Joiner, Matalsky, Katz, \& Beach, 1999, p. 270). ERS may annoy close others and lead them to reject the reassurance seeker, which may then exacerbate symptoms of depression (Joiner \& Metalsky, 1995; Joiner \& Schmidt, 1998; Potthoff, Holahan, \& Joiner, 1995). Recent research has linked anxious attachment to ERS while controlling for depression, suggesting that ERS may not arise due to symptoms of depression as previously thought, but rather due to IWMs of attachment anxiety (Evraire \& Dozois, n.d.). The current study, finding that anxiously attached individuals experienced heightened overall self-worth following positive social events and reduced overall self-worth following negative social events, suggests one mechanism by which anxious attachment might promote ERS. It may be that anxiously attached individuals engage in ERS to test a contingency of self-worth and experience heightened self-worth through others' verbal statements of approval. Empirical studies are necessary to corroborate this suggestion and may in turn help prevent individuals with anxious attachment styles from engaging in ERS and contributing to their own depressive symptomology.

The current study also found that individuals high in attachment anxiety reported relatively stable levels of self-worth following achievement-related events. This suggests that anxiously attached individuals may not create contingencies of self-worth within the achievement domain and may limit their contingencies to the social domain. These findings are consistent with the attachment literature, which suggests that as anxiously attached individuals are preoccupied with social relationships and approval, they neglect environmental exploration and achievement-related activities (Goldberg, 2000; Hepper \& Carnelley, 2010; Morley \& Moran, 2011; McElwain et al., 2003; Sroufe, 2005). Thus, anxiously attached individuals may limit contingencies of self-worth to the social domain since interpersonal factors are most relevant to their self-concepts (Hepper \& Carnelley, 2010; Morley \& Moran, 2011; Park et al., 2004).

\section{Limitations and Future Directions}

Although the current study carries important implications for the attachment and self-worth literature, a few limitations should be noted. One possible limitation in the current study is our use of the ECR-R to measure attachment. Sibley et al. (2005) found that attachment anxiety and avoidance tend to be correlated when using the ECR-R measure, however, attachment theory posits that these two attachment styles are mutually exclusive (Ainsworth et al., 1978). Despite this, attachment avoidance and anxiety were not 
significantly correlated in the current study, so it is likely that the measures of these two styles pick up on unique constructs. In addition, two review papers (Fraley et al., 2000; Sibley et al., 2005) concluded that the ECR-R is the most appropriate self-report measure of adult attachment currently available.

Another possible limitation pertains to our use of our self-report measures. The changes in self-worth that result from the outcome of an event for which an individual has staked their self-esteem may be most salient immediately following the event (Crocker \& Wolfe, 2001). Participants in the current study were asked to report how they remember their overall self-worth changing from the LECCS events (or, if the event did not occur in the past 12 months, how they feel their overall self-worth would have changed from the event). It is possible that the strength of the current findings would be heightened if participants actually experienced the life events immediately prior to reporting changes in self-worth. Thus, future studies examining contingencies of self-worth should consider using daily diary methodology in order to measure changes in self-worth immediately following actual life events.

Moreover, the use of a global self-worth scale to control for general levels of self-worth may have provided additional insight and could have ruled out baseline self-worth as a confounding variable. However, Park et al. (2004) did control for global self-esteem and still found securely attached participants to report basing self-worth on more stable, unconditional factors, relative to insecurely attached individuals. Nevertheless, future studies examining attachment style and conditional self-worth should include a measure of global self-worth as a control variable.

\section{Conclusions}

Contingencies of self-worth, and the resulting tenuous sense of self-esteem, may be particularly important for understanding the relationship between self-esteem, personality, and behavior. The current results suggest that anxiously attached individuals experience an unstable sense of self-worth and create contingencies of self-worth within the social domain, while avoidantly attached individuals may experience more stable levels of self-worth and refrain from creating contingencies of self-worth. Our results provide insight into the relational bases of self-worth and suggest that the origins of contingencies of self-worth may lie in insecure attachment representations.

\section{References}

Abela, J. R. Z., Hankin, B. L., Haigh, E. A. P., Adams, P., Vinokuroff, T., \& Trayhem, L. (2005). Interpersonal vulnerability to depression in high-risk children: The role of insecure attachment and reassurance seeking. Journal of Clinical Child \& Adolescent Psychology, 34, 182-192. doi:10.1207/s15374424jccp3401_17

Ainsworth, M. D. S., Blehar, M. C., Waters, E., \& Wall, S. (1978). Patterns of attachment: A psychological study of the strange situation. Hillsdale, N. J.: Erlbaum.

Ainsworth, M. S., \& Bowlby, J. B. (1991). An ethological approach to personality development. American Psychologist, 46, 333-341. doi:10.1037/0003-006X.46.4.333

Baldwin, M. (1997). Relational schemas as a source of if-then self-inference procedures. Review of General Psychology, 1, 326-335. doi:10.1037/1089-2680.1.4.326

Baldwin, M., \& Sinclair, L. (1996). Self-esteem and “if ... then” contingencies of interpersonal acceptance. Journal of Personality and Social Psychology, 71, 1130-1141. doi:10.1037/0022-3514.71.6.1130

Baldwin, M., Fehr, B., Keedian, E., Seidel, M., \& Thomson, D. W. (1993). An exploration of the relational schemata underlying attachment styles: Self-report and lexical decision approaches. Personality and Social Psychology Bulletin, 19, 746-754. doi:10.1177/0146167293196010 
Bartholomew, K., \& Horrowitz, L. M. (1991). Attachment styles among young adults: A test of a four-category model. Journal of Personality and Social Psychology, 61, 226-244.

Baumeister, R. F., Tice, D. M., \& Hutton, D. G. (1989). Self-presentational motivations and personality differences in self-esteem. Journal of Personality, 57, 547-579. doi:10.1111/j.1467-6494.1989.tb02384.x

Blatt, S. J., \& Homann, E. (1992). Parent-child interaction in the etiology of dependent and self-critical depression. Clinical Psychology Review, 12, 47-91. doi:10.1016/0272-7358(92)90091-L

Bowlby, J. (1969). Attachment and loss: Attachment. New York, N. Y.: Basic Books.

Bowlby, J. (1973). Attachment and loss: Separation. New York, N. Y.: Basic Books.

Bowlby, J. (1980). Attachment and loss: Loss sadness and depression. New York, N. Y.: Basic Books.

Brennan, K. A., \& Bosson, J. K. (1998). Attachment-style differences in attitudes toward and reactions to feedback from romantic partners: An exploration of the relational bases of self-esteem. Personality and Social Psychology Bulletin, 24, 699-714. doi:10.1177/0146167298247003

Brennan, K. A., Clark, C. L., \& Shaver, P. (1998). Self-report measures of adult romantic attachment. In J. A. Simpson, \& W. S. Rholes (Eds.), Attachment theory and close relationships (pp. 46-76). New York: Guilford.

Brennan, K. A., \& Morris, K. A. (1997). Attachment styles, self-esteem, and patterns of seeking feedback from romantic partners. Personality and Social Psychology Bulletin, 23, 23-31. doi:10.1177/0146167297231003

Bretherton, I., \& Munholland, K. A. (2008). Internal working models in attachment relationships: Elaborating a central construct in attachment theory. In J. Cassidy, \& P. R. Shaver (Eds.), Handbook of attachment: Theory, research, and clinical applications (pp. 102-127). New York, N. Y.: Guildford Press.

Bylsma, W. H., Cozzarelli, C., \& Sumer, N. (1997). Relation between adult attachment styles and global self-esteem. Basic and Applied Social Psychology, 19, 1-16. doi:10.1207/s15324834basp1901_1

Cohen, J. (1968). Multiple regression as a general data-analytic system. Psychological Bulletin, 70(6), 426.

Cohen, J., \& Cohen, P. (1975). Applied multiple regression/correlation analysis for the behavioral sciences. Lawrence Erlbaum.

Collins, N. L., \& Read, S. J. (1990). Adult attachment, working models, and relationship quality in dating couples. Journal of Personality and Social Psychology, 58, 644-663.

Crocker, J., Luhtanen, R. K., Cooper, M. L., \& Bouvrette, A. (2003). Contingencies of self-worth in college students: Theory and measurement. Journal of Personality and Social Psychology, 85, 894-908.

Crocker, J., \& Wolfe, C. T. (2001). Contingencies of self-worth. Psychological Review, 108, 593-623. doi:10.1037/0033-295X.108.3.593

Crocker, J. P., \& Park, L. E. (2004). The costly pursuit of self-esteem. Psychological Bulletin, 130, $392-414$. doi:10.1037/0033-2909.130.3.392

Davila, J. (2001). Refining the association between excessive reassurance seeking and depressive symptoms: The role of related interpersonal constructs. Journal of Social and Clinical Psychology, 20, 538-559.

Elliot, A. J., \& Reis, H. T. (2003). Attachment and exploration in adulthood. Journal of Personality and Social Psychology, 85, 317-331. doi:10.1037/0022-3514.85.2.317

Evraire, L. E., \& Dozois, D. J. A. (n.d.). If it be love indeed tell me how much: Early core beliefs associated with excessive reassurance seeking in depression. Canadian Journal of Behavioral Science.

Feeney, J. (2008). Adult attachment: Developments in the study of couple relationships. In J. Cassidy, \& P. R. Shaver (Eds.), Handbook of attachment: Theory, research and clinical applications (pp. 456-481). New York, N. Y.: Guilford Press.

Feeney, J. A., \& Noller, P. (1990). Attachment style predictor of adult romantic relationships. Journal of Personality and Social Psychology, 58, 281-291. doi:10.1037/0022-3514.58.2.281

Fraley, R. C., Waller, N. G., \& Brennan, K. A. (2000). An item-response theory analysis of self-report measures of adult attachment. Journal of Personality and Social Psychology, 78, 350-365.

Franks, D. D., \& Marolla, J. (1976). Efficacious action and social approval as interaction dimensions of self-esteem: A tentative formulation through contrast validation. Sociometry, 39, 466-482.

Frewen, P. A., \& Dozois, D. J. A. (2006). Self-worth appraisal of life events and beck’s congruency model of depression vulnerability. Journal of Cognitive Psychotherapy, 20, 231-240. doi:10.1891/088983906780639853

Gamble, S. A., \& Roberts, J. E. (2005). Adolescents' perceptions of primary caregivers and cognitive style: The roles of attachment security and gender. Cognitive Therapy and Research, 29, 123-141. doi:10.1007/s10608-005-3160-7

Goldberg, S. (2000). Attachment and development. London: Arnold. 
Hamilton, C. E. (2000). Continuity and discontinuity of attachment from infancy through adolescence. Child Development, 71, 690-694. doi:10.1111/1467-8624.00177

Hammen, C. (1991). Generation of stress in the course of unipolar depression. Journal of Abnormal Psychology, 100, 555-561. doi:10.1037/0021-843X.100.4.555

Hazan, C., \& Shaver, P. R. (1987). Romantic love conceptualized as an attachment process. Journal of Personality and Social Psychology, 59, 511-524.

Hazan, C., \& Shaver, P. R. (1990). Love and work: An attachment-theoretical perspective. Journal of Personality and Social Psychology, 59, 270-280.

Hepper, E. G., \& Carnelley, K. B. (2010). Adult attachment and feedbacking-seeking patterns in relationships and work. European Journal of Social Psychology, 40, 448-464.

James, W. (1890). The principles of psychology (Vol. 1). Cambridge, M. A.: Harvard University Press.

Joiner, T. E. Jr., \& Metalsky, G. I. (1995). A prospective test of an integrative interpersonal theory of depression: A naturalistic study of college roommates. Journal of Personality and Social Psychology, 69, 778-788.

Joiner, T. E. Jr., Metalsky, G. I., Katz, J., \& Beach, S. R. H. (1999). Depression and excessive reassurance seeking. Psychological Inquiry, 10, 269-278.

Joiner, T. E. Jr., \& Schmidt, N. B. (1998). Excessive reassurance-seeking predicts depression but not anxious reactions to acute stress. Journal of Abnormal Psychology, 107, 533-537.

Kuiper, N. A., Olinger, L. J., \& MacDonald, M. R. (1988). Vulnerability and episodic cognitions in a self-worth contingency model of depression. In L. B. Alloy (Ed.), Cognitive processes in depression (pp. 289-309). New York, N. Y.: Guilford Press.

McElwain, N. L., Cox, M. J., Burchinal, M. R., \& Macfie, J. (2003). Differentiating among insecure mother-infant attachment classifications: A focus on child-friend interaction and exploration during solitary play at 36 months. Attachment \& Human Development, 5, 136-164. doi:10.1080/1461673031000108513

Mikulincer, M. (1995). Attachment style and the mental representation of the self. Journal of Personality and Social Psychology, $69,1203-1215$.

Morley, T., \& Moran, G. (2011). Cognitive vulnerabilities in early childhood: Mechanisms linking early attachment to later depression. Clinical Psychology Review, 31, 1071-1082. doi:10.1016/j.cpr.2011.06.006

Park, L. E., Crocker, J., \& Mickelson, K. D. (2004). Attachment styles and contingencies of self-worth. Personality and Social Psychology Bulletin, 30, 1243-1254.

Pelham, B. W., \& Swann, W. B. (1989). From self-conceptions to self-worth: On the sources and structure of global self-esteem. Journal of Personality and Social Psychology, 57, 672-680. doi:10.1037/0022-3514.57.4.672

Potthoff, J. G., Holahan, C. J., \& Joiner, T. E. (1995). Reassurance seeking, stress generation, and depressive symptoms: An integrative model. Journal of Personality and Social Psychology, 68, 664-670. doi:10.1037/0022-3514.68.4.664

Robins, R. W., Tracy, J. L., Trzesniewski, K., Potter, J., \& Gosling, S. D. (2001). Personality correlates of self-esteem. Journal of Research in Personality, 35, 463-482. doi:10.1006/jrpe.2001.2324

Sandler, I. N., \& Lakey, B. (1982). Locus of control as a stress moderator: The role of control perceptions and social support. American Journal of Community Psychology, 10, 65-80.

Sibley, C. G., Fischer, R., \& Liu, J. H. (2005). Reliability and validity of the revised experiences in close relationships (ECR-R) self-report measure of adult attachment. Personality and Social Psychology Bulletin, 31, 1524-1536. doi:10.1177/0146167205276865

Shaver, P. R., Collins, N., \& Clark, C. L. (1996). Attachment styles and internal working models of self and relationship partners. In G. J. O. Fletcher, \& J. Fitness (Eds.), Knowledge structures in close relationships: A social psychological approach (pp. 25-53). New Jersey: Lawrence Erlbaum.

Shaver, P. R., Hazan, C., \& Bradshaw, D. (1988). Love as attachment: The integration of three behavioral systems. In R. J. Sternberg, \& M. L. Barnes (Eds.), The psychology of love (pp. 68-99). New Haven, C. T.: Yale University Press.

Shaver, P. R., Schachner, D. A., \& Mikulincer, M. (2005). Attachment style, excessive reassurance seeking, relationship processes, and depression. Personality and Social Psychology Bulletin, 31, 343-359.

Sroufe, L. A. (2005). Attachment and development: A prospective, longitudinal study from birth to adulthood. Attachment and Human Development, 7, 349-367. doi:10.1080/1461673050036928

Sroufe, L. A., Egeland, B., Carlson, E. A., \& Collins, W. A. (2005). The development of the person: The Minnesota study of risk and adaptation from birth to adulthood. New York, N. Y.: Guilford Press. 
Tafarodi, R. W., \& Swann, W. B. Jr. (1995). Self-liking and self-competence as dimensions of global self-esteem: Initial validation of a measure. Journal of Personality Assessment, 65, 322-342.

Timmons, K. A., \& Joiner, T. E. (2008). Reassurance seeking and negative feedback seeking. In K. S. Dobson, \& D. J. A. Dozois (Eds.), Risk factors in depression (pp. 289-316). Amsterdam: Elsevier Academic Press.

Waters, E., Merrick, S., Treboux, D., Crowell, J., \& Albersheim, L. (2000). Attachment security in infancy and early adulthood: A twenty-year longitudinal study. Child Development, 71, 684-689. doi:10.1111/1467-8624.00176

Ziegert, D. I., Kistner, J. A., Castro, R., \& Robertson, B. (2001). Longitudinal study of young children's responses to challenging achievement situations. Child Development, 72, 609-624. doi:10.1111/1467-8624.00300

Zuroff, D. C., \& Fitzpatrick, D. K. (1995). Depressive personality styles: Implications for adult attachment. Personality and Individual Differences, 18, 253-265. doi:10.1016/0191-8869(94)00136-G 